\title{
Do Female Rhesus Macaques Choose Novel Males?
}

\author{
JOSEPH H. MANSON \\ Department of Anthropology, University of Michigan, Ann Arbor
}

Prior research has shown that estrous female rhesus macaques (Macaca mulatta) maintain spatial proximity preferentially to lower-ranking males. In this paper, $657 \mathrm{~h}$ of focal individual follows of 48 free-ranging estrous female rhesus macaques of two social groups during two mating seasons are used to evaluate the hypothesis that this phenomenon is attributable to female mate choice for novel males. This hypothesis is plausible because of the positive correlation between dominance rank and the length of time since a male immigrated into a group or matured in his natal group (i.e., his breeding tenure). However, partial correlation analysis showed that after removing the effect of dominance rank, there was no significant tendency for estrous females to maintain proximity preferentially to males of shorter breeding tenure. In contrast, removing the effect of breeding tenure did not eliminate the result that estrous females maintained proximity preferentially to lower ranking males. Novel (i.e., extragroup, new immigrant, and newly matured natal) males did not consistently experience more estrous female proximity maintenance than nonnovel males, although sample sizes are too small to conclusively falsify this hypothesis. Within male-estrous female dyads, responsibility for proximity maintenance did not tend to shift from the female to the male between consecutive mating seasons. Male breeding tenure was not significantly correlated with year-to-year change in responsibility for proximity maintenance. Male breeding tenure was not consistently correlated with female sexual refusal. In one of two social groups, in one of two mating seasons, females appeared to choose novel males. These data provide, at most, weak support for the hypothesis that female primates in multi-male groups exercise mate choice for novel males. (C) 1995 Wiley-Liss, Inc.

\section{Key words: mate choice, Macaca mulatta, Cayo Santiago}

\section{INTRODUCTION}

Female nonhuman primates often engage in behavior patterns that increase the number of copulatory partners to which they are exposed during a single breeding episode [for reviews see Hrdy, 1981; Small, 1993]. These behavior patterns have been interpreted by several authors as products of selection on females to exercise mate choice for sexually novel males [Wolfe, 1986; Huffman, 1991,

Received for publication June 6, 1994; revision accepted February 19, 1995.

Address reprint requests to Dr. Joseph H. Manson, Department of Anthropology, UCLA, 405 Hilgard Avenue, Los Angeles, CA 90095-1553. 
TABLE I. Composition of Study Groups by Age-Sex Class*

\begin{tabular}{|c|c|c|c|c|}
\hline \multirow[b]{2}{*}{ Age-sex class } & \multicolumn{2}{|c|}{ Group Q } & \multicolumn{2}{|c|}{ Group T } \\
\hline & June 1988 & June 1989 & June 1988 & June 1989 \\
\hline Adult males & $25(4)$ & $24(6)$ & $31(3)$ & $37(7)$ \\
\hline Subadult males & $6(5)$ & $3(3)$ & $6(3)$ & $5(5)$ \\
\hline Adult females & 30 & 36 & 21 & 27 \\
\hline Adolescent females & 7 & 6 & 6 & 4 \\
\hline Juveniles and infants & 58 & 74 & 40 & 53 \\
\hline Total & 126 & 142 & 104 & 126 \\
\hline
\end{tabular}

*Adult males: $\geq 5.5$ years old. Subadult males: 4.5 years old. Numbers in parentheses denote numbers of natal males. Adult females: $\geq 4.5$ years old. Adolescent females: 3.5 years old.

1992; Small, 1993]. Specifically, female choice for novelty has been hypothesized to (1) deter infanticide [Hrdy, 1981], (2) produce genetically diverse sets of offspring [Wolfe, 1986; Small, 1993; see also Murray, 1980; Ripley, 1980], and/or (3) prevent incestuous copying of mate choices by females' daughters [Huffman, 1992]. Alternatively, choice for novelty in large, provisioned multi-male groups may represent the non-adaptive manifestation of behavioral propensities that function to prevent inbreeding in small unprovisioned groups [Takahata, 1982].

In this paper, data from free-ranging rhesus macaques are used to address an issue that has been raised by several authors: when females in multi-male groups choose males other than the most dominant, possibly incurring the cost of increased male aggression [Huffman, 1987; Manson, 1994a], does this reflect female mate choice for novelty? Group tenure and male dominance rank are closely, but not perfectly, correlated in rhesus and Japanese macaques [Drickamer \& Vessey, 1973; Sugiyama, 1976]. Group tenure reflects, though not perfectly, social and possibly sexual familiarity. In this paper, I seek to determine whether estrous female rhesus macaques' tendency to maintain proximity preferentially to lowerranking males [Manson, 1992] can be explained as mate choice for novelty. It also examine whether female sexual refusals are directed preferentially toward males with longer tenure. The analyses reported here, although they address a previously unexplored issue, are based on the same set of observations that formed the basis of earlier work [Manson, 1992, 1994a,b; Manson \& Perry, 1993].

\section{METHODS}

\section{Study Species and Site}

The subjects of my study were 65 adult (4.5 years and older) female rhesus macaques of two social groups (groups T and Q) on Cayo Santiago, a 15 ha island $1 \mathrm{~km}$ off the southeast coast of Puerto Rico (Table I). The monkeys of Cayo Santiago are provisioned and are trapped annually for identification marking. A biweekly census of the entire population updates a database of births, deaths, intergroup transfers, and group fissions covering the entire period since 1956. Periodic removal of entire social groups keeps the population between approximately $600-$ 1,400 . Otherwise, the monkeys are free-ranging and are not handled or interfered with [for more information about Cayo Santiago management and history, see Altmann, 1962; Sade et al., 1985; Rawlins \& Kessler, 1986].

Social groups on Cayo Santiago range in size from 50-300 animals, in contrast to the 10-140 range observed in wild and feral rhesus on the Indian subcontinent [e.g., Malik et al., 1984; Melnick et al., 1984]. Adult sex ratios within groups are 
approximately 1:1 at Cayo Santiago, whereas in groups on the subcontinent females outnumber males 2-3:1.

\section{Measures and Definitions}

Behavioral endocrinological studies of captive rhesus macaques [Catchpole \& van Wagenen, 1978; Gordon, 1981] show that ovulation occurs during the 4 days preceeding the "attractiveness breakdown" [Chapais, 1983], i.e., the sharp decrease (usually from one day to the next) in the female's sexual attractiveness. The attractiveness breakdown is recognizable by either the end of all sexual activity, or less commonly, the beginning of a 1- to 2-day period culminating in the end of all sexual activity and characterized by the (1) marked decrease in proceptive behavior, (2) complete cessation of following and courtship by high-ranking males, and (3) toleration by these males of occasional copulations with low-ranking males in plain view (behavior that would have provoked male aggression earlier in the estrous period). The 4 days preceding the attractiveness breakdown will be called the Peri-ovulatory period. Rhesus macaques are series mounters. The final ejaculatory mount is discernible by a characteristic pause and rigid posture by the male. I defined mount series culminating in ejaculation as "copulations." All analyses in this paper that use copulatory rate as a variable refer to copulations as defined here; incomplete mount series are not included. Because rhesus macaque females do not exhibit reliable morphological signs of estrus, a female was regarded as being in estrus from the day she was first seen in a mount series, or with a mating plug (coagulated ejaculate on her perineum), until the day after her attractiveness breakdown.

A dominance interaction was scored whenever one animal supplanted another (approached and took its spot immediately after the approached animal vacated it) or when the approach of one animal caused another to "grimace" (retract the lips and cheeks, exposing the teeth), "cower" (lean downward and away from the approaching animal), or flee. Adult male dominance relationships were ascertained by arranging males in matrices showing winners of dominance interactions along one axis and losers along the other.

An "approach" was scored when one animal decreased the distance between itself and another animal by at least $1 / 2 \mathrm{~m}$ and stopped or sat, with the final distance between them being less than $4 \mathrm{~m}$. A "leave" was scored when one animal increased the distance between itself and another animal by at least $1 / 2 \mathrm{~m}$, with the initial distance between them being less than $4 \mathrm{~m}$. Approaches and leaves taking place at the artificial drinking stations were excluded from analyses, as were "leaves" during chases.

For each male-estrous female dyad in which the sum of observed approaches and leaves was at least 10, I calculated Hinde's index [Hinde \& Atkinson, 1970] by subtracting the proportion of all female leaves within the dyad from the proportion of all female approaches within the dyad. This index measures responsibility for maintaining spatial proximity. Its value can very from -1.00 (the male is entirely responsible for maintaining proximity) to +1.00 (the female is entirely responsible for maintaining proximity). The cut-off of 10 summed approaches and leaves, set arbitrarily before data were analyzed, increases the reliability of Hinde's index as a measure of dyadic relationships. The Hinde's indices calculated were averaged to give each male with at least one index a mean Hinde's index (MHI). In the calculation of natal males' MHIs, Hinde's indices with matrilineal relatives were excluded [see Manson, 1992].

A "sexual refusal" was scored when a female responded to a male's "hip-grasp" (grasping the female's hips with both hands from behind) by refusing to "present" 


\section{8 / Manson}

(stand up to be mounted) to begin a mount series. Females refused by either remaining seated or moving away. For each male, a "refusal proportion" was calculated as the mean proportion of hip-grasps refused, averaged across all females that he hip-grasped at least once.

The following data were obtained from the Cayo Santiago long-term database for each individual in both study groups: (1) age in years, (2) matriline (for females and natal males only), and (3) for males, breeding tenure in months (since entering the group for immigrants, and since June of the male's fifth year for natal males). Because of the possibility that breeding females' past social interactions with immature natal males affected adult sexual interactions between them, analyses presented here were also carried out with natal males excluded. Figure 1 shows the distributions of male breeding tenures in the two study groups at the beginning of the two mating seasons of the study.

\section{Data Collection and Analysis}

Data were collected on 162 days during one complete mating season (JuneOctober 1988) and 49 days of a second mating season (June-August 1989). Two observers were present during most days of the 1988 mating season, compared to four in the 1989 mating season. Ad libitum [Altmann, 1974] observations provided information about dominance relationships and cycling females' reproductive states. Observers conducted 2-h focal individual follows [Altmann, 1974], divided into 30 -min sampling blocks with no more than $5 \mathrm{~min}$ between them, on females chosen randomly from those judged to be in estrus on the preceding day. Data from uncompleted 2-h follows were used in the analyses described here, except for uncompleted 30-min sampling blocks, which were discarded. During follows, checksheets were used to record all approaches and leaves, and all occurrences of 54 social behaviors, displayed by or directed toward the focal female. Observers also recorded the female's current activity, nearest adult male neighbor, and other adult neighbors within $10 \mathrm{~m}$ every $3 \mathrm{~min}$ on an instantaneous basis. Follows were temporarily discontinued when focal subjects entered the fenced-in feeding corrals.

To ensure inter-observer reliability, all observers were required to meet a standard of $90 \%$ concordant records with mine, over four consecutive 30 -min focal follows. Data collected during these test sessions were not analyzed.

Sample sizes (number of dyads) vary in the analyses described below because all variables of interest could not be calculated for every dyad or every individual. For instance, some males did not have 10 approaches + leaves with any estrous female. These males, however, were still used in some statistical tests, such as the correlation of male breeding tenure and dominance rank.

Significance of results was determined using nonparametric statistical tests. Kendall partial correlation significance levels are from Maghsoodloo [1975] and Maghsoodloo and Laszlo Pallos [1981]. All tests are two-tailed.

\section{RESULTS}

A total of $716 \mathrm{~h}$ of focal data on estrous females were collected. Of these, $59 \mathrm{~h}$ of focal data collected on 14 females were discarded because subjects were in estrus on the last day of data collection (August 18, 1989), raising problems of data censorship. Thus, $657 \mathrm{~h}$ of focal data on 48 estrous females were available for analysis. Table II shows the numbers of focal subjects and focal hours collected in each mating season in each social group. The substantial difference between group $\mathrm{Q}$ and group $\mathrm{T}$ in number of focal hours collected in 1989 resulted from the fact that, in general, group $\mathrm{T}$ females' first estrous periods started later than group $\mathrm{Q}$ females' estrous periods. Fewer group T females had begun their first estrus by the 

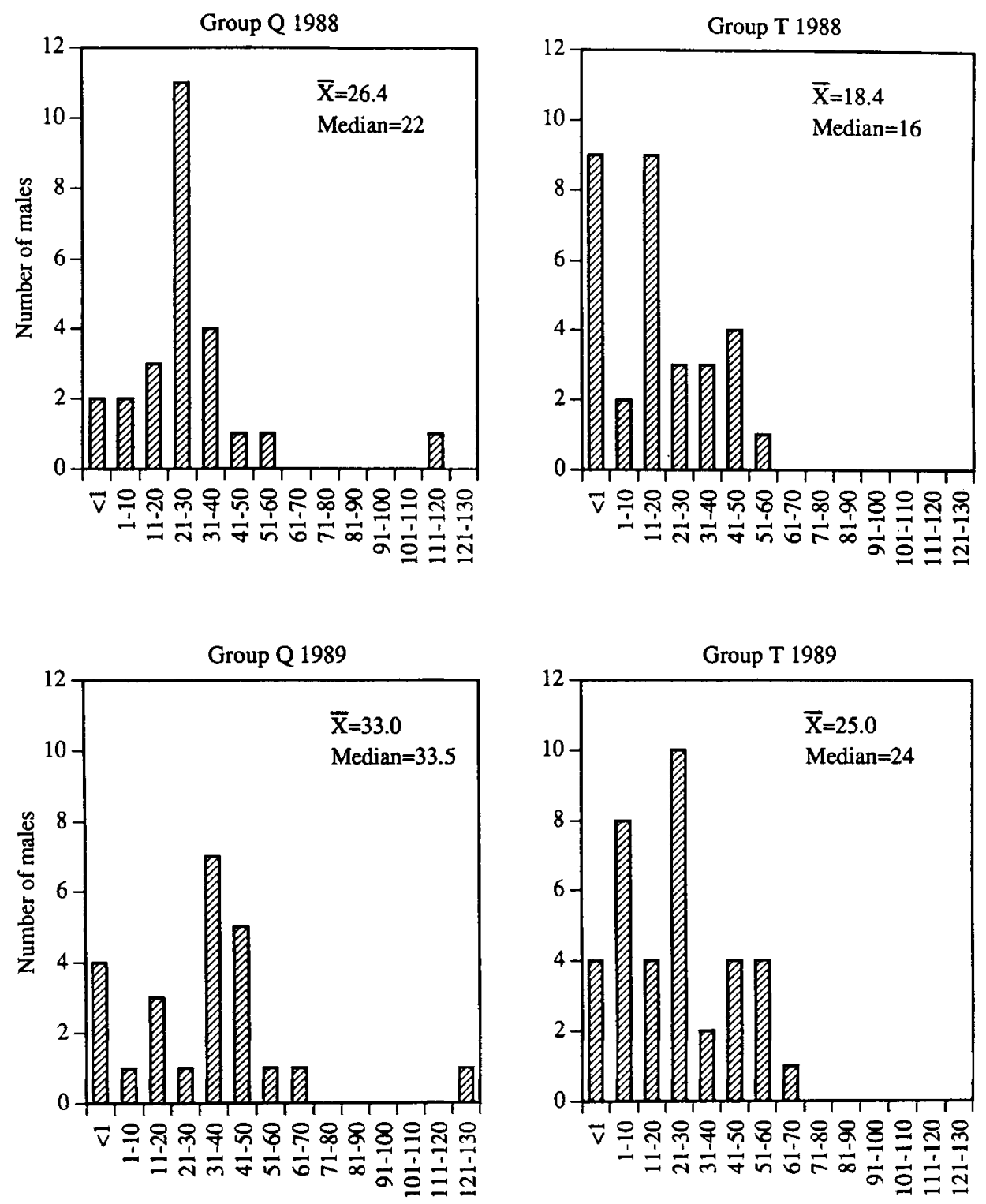

Tenure in months

Fig. 1. Frequency distributions of male breeding tenure lengths. Data from each social group in each mating season is shown separately.

end of the study. Small sample sizes in group $\mathrm{T}$ in 1989 compel caution in making inferences based on that sample.

\section{Male Dominance and Breeding Tenure}

In both study groups in both mating seasons, adult males ( 5.5 years and older) formed linear hierarchies, as indicated by the dominance matrices that were con- 
TABLE II. Numbers of Focal Subjects and Focal Hours

\begin{tabular}{lccccc}
\hline & \multicolumn{2}{c}{ Group Q } & & \multicolumn{2}{c}{ Group T } \\
\cline { 2 - 3 } \cline { 5 - 6 } & 1988 & 1989 & & 1988 & 1989 \\
\hline Focal subjects & 23 & 18 & & 16 & 8 \\
Focal hours & 119.5 & 345 & & 123 & 69.5 \\
X hours/subject \pm SD & $5.2 \pm 3.3$ & $19.2 \pm 21.6$ & & $7.7 \pm 4.8$ & $8.7 \pm 4.4$ \\
\hline
\end{tabular}

structed; i.e., all observed interactions were on the same side of the diagonal. The dominance relationships of some dyads of low-ranking males could not be determined because we observed no interactions between the two animals. Males of uncertain dominance rank (8-38.7\% of males, depending on year and social group) were assigned a rank that was the median rank of all the males of uncertain rank in their social group. All males of uncertain dominance rank were subordinate to all males of known dominance rank. In the analyses that follow, male dominance rank is expressed as the proportion of males dominated within the social group.

In both groups in both mating seasons, males with longer breeding tenures held higher dominance ranks than males with shorter breeding tenures (group $\mathrm{T}$ 1988: Kendall's $\tau=.431, \mathrm{n}=31$ males, $P=.0007$; group Q 1988: $\tau=.586, \mathrm{n}=$ $25, P=.0001 ;$ group T 1989: $\tau=.35, \mathrm{n}=37, P=.0023$; group $\mathrm{Q} 1989: \tau=.616$, $\mathrm{n}=24, P=.0001)$.

\section{Female Mate Choice: Tactics and Costs}

Males' contributions to the data set of mean Hinde's indices (MHI) are shown in Table III. Previously reported results [Manson, 1992, 1994a] from this study include the findings that (1) in comparisons among heterosexual dyads, female proximity maintenance correlated positively with peri-ovulatory copulation rate in group Q; (2) estrous females maintained proximity preferentially to lower-ranking males (i.e., lower-ranking males had higher MHI) in group Q in both mating seasons, and in group $\mathrm{T}$ in 1988; (3) estrous females suffered higher rates of attack by intruding males while with low-ranking males than while with high-ranking males; and (4) heterosexual dyads in which the female refused a smaller proportion of hip-grasps copulated at higher rates during the female's peri-ovulatory period. Whether male breeding tenure affects estrous female behavior toward males has not yet been addressed.

\section{Male Dominance and Breeding Tenure and Female Mate Choice}

Simple and partial correlation analyses, illustrated in Table IVa, show that although males with longer breeding tenure had significantly lower MHIs (i.e., they experienced less female proximity maintenance) than those with shorter breeding tenure in two of four group-years, these results became non-significant when male dominance rank was held constant. In contrast, when breeding tenure was held constant, dominance rank remained significantly negatively correlated with $\mathrm{MHI}$ in three of four group-years. Removing natal males from the analysis did not alter these results (Table IVb). To test whether female proximity maintenance was influenced by male novelty in dichotomous fashion (novel vs. non-novel), males with at least one calculated Hinde's index (see Methods) were divided into two categories. "Novel males" were defined as those that had (1) entered the social group or reached age 5.5 years since the preceding mating season or (2) were solitary or belonged to a different social group from the focal female, yet had at least 10 summed approaches and leaves with at least 1 female of the social group. 
Novelty and Rhesus Female Choice

TABLE III. Males' Contributions to the Data Set of Mean Hinde's Indices (MHI)

\begin{tabular}{lccccc}
\hline & \multicolumn{2}{c}{ Group Q } & & \multicolumn{2}{c}{ Group T } \\
\cline { 2 - 3 } \cline { 5 - 6 } & 1988 & 1989 & & 1988 & 1989 \\
\hline Males contributing $\geq 1$ MHI & 20 & 22 & & 25 & 12 \\
$\bar{X} \pm$ SD MHI/male & $5.3 \pm 3.1$ & $5.2 \pm 3.3$ & & $4.0 \pm 3.3$ & $2.4 \pm 2.2$ \\
Range & $1-12$ & $1-12$ & & $1-11$ & $1-7$ \\
\hline
\end{tabular}

Other males were classified as "non-novel." Table V shows that novel males had significantly higher MHIs than non-novel males only in group Q in 1989. Note, however, that this was the group-year in which the number of novel males was greatest, and that trends toward higher MHI for novel males were also apparent in the other group-years. In group $Q$ in each year, one novel male was a natal male; removing novel natal males did not change the significance of the results.

If females choose less familiar males, male-estrous female dyads should consistently show decreases in Hinde's index in consecutive years. Yet Hinde's index increased in $23 / 43(53.5 \%)$ of these dyads, and decreased in the remaining $20 / 43$ $(46.5 \%)$.

If females begin to disfavor males only after residing in the same group for two or more years, then heterosexual dyads in which the male has longer breeding tenure should be more likely to show decreases in Hinde's index in consecutive years than dyads in which the male has shorter breeding tenure. For dyads with Hinde's indices in both 1988 and 1989, male breeding tenure was not significantly correlated with change in Hinde's index $(\tau=.12, \mathrm{n}=43, P=.25)$.

Table VIa shows that neither male dominance rank nor breeding tenure was consistently related to proportion of hip-grasps refused. Only in group Q in 1989 were both hypothesized independent variables significantly correlated with refusal proportion. Partial correlation analysis of that sample showed that when dominance rank was held constant, breeding tenure remained significantly correlated with refusal proportion (i.e., males with longer tenure had more hip-grasps refused), whereas when breeding tenure was held constant, dominance rank was no longer significantly associated with refusal proportion. Removing natal males from the analysis (Table VIb) produced a significant positive correlation between dominance rank and refusal proportion in group $Q$ in 1989, and reduced to marginal significance the partial correlation between breeding tenure and refusal proportion (with dominance rank held contant) in group Q in 1989.

\section{DISCUSSION}

Data presented here provide, at most, weak support for the hypothesis that female rhesus macaques choose novel males as mates. Anecdotal reports of such choices by female macaques [e.g., Brereton, 1981; Burton \& Fukuda, 1981; Wolfe, $1986]$ are similar to some incidents that were observed in group $Q$ in 1989. Completed peri-ovulatory copulations with non-group $Q$ males accounted for $15 / 68$ (22\%) of observed completed peri-ovulatory copulations, and involved 8/16 (50\%) of the group $Q$ females that were observed to complete at least one peri-ovulatory copulation during that mating season. Females initiated these copulations by actively "sneaking off" with extra-group males to locations far from other group Q monkeys. Similarly, Berard et al. (1993) report at least $4 / 11$ (36.4\%) group S infants were sired by non-group $\mathrm{S}$ males in one mating season. However, quantitative analysis of my data set failed to find a consistent effect (across years and social groups) of male novelty on female mate choice behavior. Male breeding tenure had 


\section{2 / Manson}

TABLE IVa. Simple and Partial Kendall's $\tau$ Correlations Between Male Dominance Rank and Breeding Tenure (Independent Variables) and Mean Hinde's Index (Dependent Variable) Including All Males

\begin{tabular}{lccccc}
\hline & & \multicolumn{4}{c}{ Sample } \\
\cline { 3 - 6 } $\begin{array}{l}\text { Independent } \\
\text { variable }\end{array}$ & $\begin{array}{c}\text { Variable held } \\
\text { constant }\end{array}$ & $\begin{array}{c}\text { Group T 1988 } \\
(\mathrm{N}=25)\end{array}$ & $\begin{array}{c}\text { Group Q 1988 } \\
(\mathrm{N}=20)\end{array}$ & $\begin{array}{c}\text { Group T 1989 } \\
(\mathrm{N}=12)\end{array}$ & $\begin{array}{c}\text { Group Q 1989 } \\
(\mathrm{N}=22)\end{array}$ \\
\hline Breeding tenure & - & -.20 & $-.43^{* *}$ & -.28 & $-.35^{*}$ \\
Breeding tenure & Dominance rank & -.07 & -.21 & -.23 & -.09 \\
Dominance rank & Breeding tenure & $-.37^{* *}$ & $-.43^{* *}$ & -.22 & $-.33^{*}$ \\
\hline
\end{tabular}

$* P<.05 ; * * P<.01$.

TABLE IVb. Simple and Partial Kendall's $\tau$ Correlations Between Male Dominance Rank and Breeding Tenure (Independent Variables) and Mean Hinde's Index (Dependent Variable) Including Non-Natal Males Only

\begin{tabular}{lccccc}
\hline & & \multicolumn{4}{c}{ Sample } \\
\cline { 3 - 6 } $\begin{array}{l}\text { Independent } \\
\text { variable }\end{array}$ & $\begin{array}{c}\text { Variable held } \\
\text { constant }\end{array}$ & $\begin{array}{c}\text { Group T 1988 } \\
(\mathrm{N}=22)\end{array}$ & $\begin{array}{c}\text { Group Q 1988 } \\
(\mathrm{N}=15)\end{array}$ & $\begin{array}{c}\text { Group T 1989 } \\
(\mathrm{N}=9)\end{array}$ & $\begin{array}{c}\text { Group Q 1989 } \\
(\mathrm{N}=16)\end{array}$ \\
\hline Breeding tenure & - & $-.33^{*}$ & $-.44^{*}$ & -.37 & -.35 \\
Breeding tenure & Dominance rank & -.11 & -.26 & -.33 & .00 \\
Dominance rank & Breeding tenure & $-.38^{* *}$ & $-.53^{* *}$ & -.12 & $-.40^{*}$ \\
\hline
\end{tabular}

$* P<.05 ;{ }^{* *} P<.01$.

no significant effect, independently of the effect of male dominance rank, on estrous female proximity maintenance. Only in group Q in 1989, estrous females (1) maintained proximity significantly more actively to novel (new immigrant, extragroup, and newly mature natal) males than to non-novel males and (2) refused more hip-grasps by males of longer breeding tenure. However, with respect to the former result, trends were consistently (across groups and years) in the direction of greater proximity maintenance toward novel males. Heterosexual dyadic Hinde's indices did not consistently decline between the 1988 and 1989 mating seasons; in fact, there was a non-significant tendency for them to rise. Nor was male breeding tenure significantly associated with the magnitude of these year-to-year changes.

The hypothesis that male novelty affects sexual attractiveness in rhesus macaques cannot be unequivocally rejected. The behavior of the group $Q$ females in 1989 suggests that females choose extra-group males under certain circumstances. Because this study incorporated data from only 2 social groups in 2 mating seasons, the nature of these circumstances cannot be assessed systematically, but two hypotheses can be suggested. First, females may choose novel males when the average breeding tenure of the males of their own group is especially long. Figure 1 shows that average male breeding tenure was longest among the group $Q$ males in 1989. Statistical tests of the differences in breeding tenure among the four sets of males cannot be performed because of non-independence problems: most of the males of each group in 1989 also resided in that group in 1988. Second, female mate choice may be less constrained by male mating tactics (sequestering, aggression) [see Manson 1994a] when male:female ratios are lower [Berenstain \& Wade, 1983]. Table I shows that the male:female ratio was lowest in group $Q$ in 1989 . The distinction between mate choice (behavior that alters the probability of mating [Halliday, 1983]) and mate preference (underlying propensity [Heisler et al., 1987]) is important here. Females may often prefer novel males but (at least at 
TABLE V. Male Novelty and Mean Hinde's Index (MHI)

\begin{tabular}{lcccc}
\hline & Group T 1988 & Group T 1989 & Group Q 1988 & Group Q 1989 \\
\hline $\mathrm{N}_{\text {novel males }}$ & 3 & 0 & 6 & 20 \\
$\overline{\mathrm{X}}_{\text {MHI }}$ novel males & .18 & - & .23 & .32 \\
$\mathrm{~N}_{\text {non-novel males }}$ & 25 & 12 & 19 & 18 \\
$\overline{\mathrm{X}}_{\text {MHI }}$ & .05 & .15 & .06 & -.01 \\
Mann-Whovel males & 25 & - & 36.5 & $35.5^{*}$ \\
\hline
\end{tabular}

$* P<.01$.

TABLE VIa. Simple and Partial Kendall's $\tau$ Correlations Between Male Dominance Rank and Breeding Tenure (Independent Variables) and Refusal Proportion (Dependent Variable) Including All Males

\begin{tabular}{lccccc}
\hline & & \multicolumn{5}{c}{ Sample } \\
\cline { 3 - 6 } Independent & $\begin{array}{c}\text { Variable held } \\
\text { variable }\end{array}$ & $\begin{array}{c}\text { Group T 1988 } \\
(\mathrm{N}=21)\end{array}$ & $\begin{array}{c}\text { Group T 1989 } \\
(\mathrm{N}=17)\end{array}$ & $\begin{array}{c}\text { Group Q 1988 } \\
(\mathrm{N}=17)\end{array}$ & $\begin{array}{c}\text { Group Q 1989 } \\
(\mathrm{N}=19)\end{array}$ \\
\hline Breeding tenure & - & -.01 & .07 & .16 & $.48^{* * *}$ \\
Dominance rank & - & .02 & .18 & $.35^{*}$ & $.33^{* *}$ \\
Breeding tenure & Dominance rank & -.02 & .01 & -.06 & $.37^{* *}$ \\
Dominance rank & Breeding tenure & .03 & .17 & $.32^{*}$ & .07 \\
\hline
\end{tabular}

${ }^{*} .05<P<.10 ;{ }^{* *} P<.05 ;{ }^{* * *} P<.01$.

TABLE VIb. Simple and Partial Kendall's $\tau$ Correlations Between Male Dominance Rank and Breeding Tenure (Independent Variables) and Refusal Proportion (Dependent Variable) Including Non-Natal Males Only

\begin{tabular}{lccccc}
\hline & & \multicolumn{4}{c}{ Sample } \\
\cline { 3 - 6 } $\begin{array}{l}\text { Independent } \\
\text { variable }\end{array}$ & $\begin{array}{c}\text { Variable held } \\
\text { constant }\end{array}$ & $\begin{array}{c}\text { Group T 1988 } \\
(\mathrm{N}=19)\end{array}$ & $\begin{array}{c}\text { Group T 1989 } \\
(\mathrm{N}=13)\end{array}$ & $\begin{array}{c}\text { Group Q 1988 } \\
(\mathrm{N}=12)\end{array}$ & $\begin{array}{c}\text { Group Q 1989 } \\
(\mathrm{N}=14)\end{array}$ \\
\hline Breeding tenure & - & -.02 & .10 & .33 & $.53^{* * *}$ \\
Dominance rank & - & .03 & .22 & $.64^{* * *}$ & $.46^{* *}$ \\
Breeding tenure & Dominance rank & -.05 & -.02 & .07 & $.34^{*}$ \\
Dominance rank & Breeding tenure & .06 & .20 & $.58^{* * *}$ & .17 \\
\hline
\end{tabular}

${ }^{*} .05<P<.10 ;{ }^{* * P}<.05 ;{ }^{* * *} P<.01$.

Cayo Santiago) seldom be able to exercise this preference. Further investigation of the conditions eliciting rhesus macaque female mate choice for novelty should include experimental manipulation of hypothesized independent variables in captivity, as well as additional observation of free-ranging populations.

Over short periods (between consecutive mating seasons), Cayo Santiago females showed consistency in their mate choices. Manson [1992] reported that male-estrous female Hinde's indices of 1988 were significantly positively correlated with Hinde's indices of 1989 in the dyads that had ten or more summed approaches and leaves in both mating seasons, even controlling for male dominance rank (see Fedigan and Gouzoules [1978] for similar results in Japanese macaques). If males become sexually unattractive only after very long (4 years) tenures, observed distributions of breeding tenures show that most males transfer before experiencing a tenure-related decline in attractiveness. The alpha male of group Q, an immigrant with a tenure of 111 months at the beginning of the 1988 mating season (see Fig. 1), experienced the third lowest MHI in the group in 1988, 


\section{4 / Manson}

the lowest $\mathrm{MHI}$ in the group in 1989 , and completed no peri-ovulatory copulations with adult females in either mating season. Continued residence in a social group by high-ranking males of long tenure, despite declining mating opportunities, has been suggested to function to protect offspring sired in past years [Bernstein, 1976]. However, whether male rhesus macaques form special affliative relationships with past copulatory partners, which would effectively enable them to protect likely offspring, is unclear. Neither Hill [1990] nor Manson [1994b] found concordance between mating activity and subsequent birth season heterosexual affiliative relationships in Cayo Santiago rhesus macaques.

Female mate choice for new immigrant, extra-group, or extra-pair males has been reported for several primate species (e.g., savanna baboons Papio cynocephalus anubis [Bercovitch, 1991; see also Packer, 1979]; vervets Cercopithecus aethiops [Henzi \& Lucas, 1980]; blue monkeys C. mitis [Tsingalia \& Rowell, 1984]; long-tailed macaques Macaca fascicularis [van Noordwijk, 1985]; hanuman langurs Presbytis entellus [Hrdy, 1977]; siamangs Hylobates syndactylus [Palombit, 1994]). However, the theoretical basis for expecting female primates to choose novel males requires further development before researchers can formulate clear hypotheses about (1) the statistical relationship between male (un)familiarity and sexual attractiveness and (2) how this relationship will vary as a function of ecological, social, demographic, and phylogenetic variables.

\section{CONCLUSIONS}

1. When male dominance rank is held constant, male breeding tenure is not significantly correlated with proximity maintenance by estrous female rhesus macaques. When breeding tenure is held constant, lower-ranking males experience more estrous female proximity maintenance than higher-ranking males.

2 . Novel males do not consistently experience significantly more estrous female proximity maintenance than non-novel males, although trends in this direction are apparent.

3. Within male-estrous female dyads, responsibility for proximity maintenance does not consistently shift from the female to the male between consecutive mating seasons. Male breeding tenure is not significantly correlated with year-toyear change in responsibility for proximity maintenance. fusal.

4. Male breeding tenure is not consistently correlated with female sexual re-

\section{ACKNOWLEDGMENTS}

I thank Barbara Gault, Julie Gros-Louis, Ann Lake, and Susan Perry for data collection. Kim Hill, Warren Holmes, Michael Huffman, John Mitani, Susan Perry, Barbara Smuts, and three anonymous reviewers commented on earlier drafts of the manuscript. Matt Kessler and John Berard of the Caribbean Primate Research Center gave permission to conduct this study. This research was supported by the Leakey Foundation, NSF (BNS-8816132), and two units of the University of Michigan: the Rackham School of Graduate Studies and the Evolution and Human Behavior Program. Cayo Santiago was supported by the University of Puerto Rico, and NIH grant P40-RR03640-03.

\section{REFERENCES}

Altmann, J. Observational study of behaviour: Sampling methods. BEHAVIOUR 49: $227-265,1974$.

Altmann, S.A. A field study of the sociobiology of rhesus monkeys (Macaca mulatta).
ANNALS OF THE NEW YORK ACADEMY OF SCIENCES 102:338-435, 1962 .

Berenstain, L.; Wade, T.D. Intrasexual selection and mating strategies in baboons and 
macaques. INTERNATIONAL JOURNAL OF PRIMATOLOGY 4:201-235, 1983.

Berard, J.D.; Nürnberg, P.; Epplen, J.T.; Schmidtke, J. Male rank, reproductive behavior, and reproductive success in freeranging rhesus macaques. PRIMATES 34 : 481-489, 1993.

Bercovitch, F.B. Mate selection, consortship formation, and reproductive tactics in adult female savanna baboons. PRIMATES 32:437-452, 1991.

Bernstein, I.S. Dominance, aggression and reproduction in primate societies. JOURNAL OF THEORETICAL BIOLOGY 60: 459-472, 1976.

Brereton, A. Intertroop consorting by a freeranging female rhesus monkey. PRIMATES 22:417-423, 1981.

Burton, F.D.; Fukuda, F. On female mobility: The case of the Yugawara-T group of Macaca fuscata. JOURNAL OF HUMAN EVOLUTION 10:381-386, 1981.

Catchpole, H.R.; van Wagenen, G. Reproduction in rhesus monkeys, Macaca mulatta. Pp. 118-139 in THE RHESUS MONKEY. G.H. Bourne, ed. New York, Academic Press, 1978.

Chapais, B. Reproductive activity in relation to male dominance and the likelihood of ovulation in rhesus monkeys. BEHAVIORAL ECOLOGY AND SOCIOBIOLOGY 12:215-228, 1983.

Drickamer, L.C.; Vessey, S. Group changing in free-ranging male rhesus monkeys. PRIMATES 14:359-368, 1973.

Fedigan, L.M.; Gouzoules, H. The consort relationship in a troop of Japanese monkeys. Pp. 493-495 in RECENT ADVANCES IN PRIMATOLOGY, VOL. 1. D.J. Chivers; J. Herbert, eds. New York, Academic Press, 1978.

Gordon, T.P. Reproductive behavior in the rhesus monkey: Social and endocrine variables. AMERICAN ZOOLOGIST 21:185$195,1981$.

Halliday, T.R. The study of mate choice. Pp. 3-22 in MATE CHOICE. P. Bateson, ed. Cambridge, Cambridge University Press, 1983.

Heisler, L.; Andersson, M.B.; Arnold, S.J.; Boake, C.R.; Borgia, G.; Hausfater, G.; Kirkpatrick, M.; Lande, R.; Maynard Smith, J.; O'Donald, P.; Thornhill, R.; Weissing, F.J. The evolution of mating preferences and sexually selected traits. Pp. 97-118 in SEXUAL SELECTION: TESTING THE ALTERNATIVES. J.W. Bradbury; M.B. Andersson, eds. New York, Wiley, 1987.

Henzi, S.P.; Lucas, J.W. Observations on the intertroop movement of adult vervet monkeys (Cercopithecus aethiops). FOLIA PRIMATOLOGICA 33:220-235, 1980.
Hill, D.A. Social relationships between adult male and female rhesus macaques: II. Nonsexual affiliative behavior. PRIMATES 31: 33-50, 1990.

Hinde, R.A.; Atkinson, S. Assessing the roles of social partners in maintaining mutual proximity as exemplified by motherinfant relations in rhesus monkeys. ANIMAL BEHAVIOUR 18:169-176, 1970.

Hrdy, S.B. THE LANGURS OF ABU. Cambridge, Harvard University Press, 1977.

Hrdy, S.B. THE WOMAN THAT NEVER EVOLVED. Cambridge, Harvard University Press, 1981.

Huffman, M.A. Consort intrusion and female mate choice in Japanese macaques (Macaca fuscata). ETHOLOGY 75:221$234,1987$.

Huffman, M.A. Mate selection and partner preferences in female Japanese macaques. Pp. 101-122 in THE MONKEYS OF ARASHIYAMA: THIRTY-FIVE YEARS OF RESEARCH IN JAPAN AND THE WEST. L.M. Fedigan; P. Asquith, eds. Albany, NY, SUNY Press, 1991.

Huffman, M.A. Influences of female partner preference on potential reproductive outcome in Japanese macaques. FOLIA PRIMATOLOGICA 59:77-88, 1992.

Maghsoodloo, S. Estimates of the quantiles of Kendall's partial rank correlation coefficient. JOURNAL OF STATISTICAL COMPUTATION AND SIMULATION 4:156-164, 1975.

Maghsoodloo, S.; Laszlo Pallos, L. Asymptotic behavior of Kendall's partial rank correlation coefficient and additional quantile estimates. JOURNAL OF STATISTICAL COMPUTATION AND SIMULATION 13: 41-48, 1981.

Malik, I.; Seth, P.K.; Southwick, C.H. Population growth of free-ranging rhesus monkeys at Tughlaqabad. AMERICAN JOURNAL OF PRIMATOLOGY 7:311-321, 1984.

Manson, J.H. Measuring female mate choice in Cayo Santiago rhesus macaques. ANIMAL BEHAVIOUR 44:405-416, 1992.

Manson, J.H. Male aggression: A cost of female mate choice in Cayo Santiago rhesus macaques. ANIMAL BEHAVIOUR 48: 473-475, 1994a.

Manson, J.H. Mating patterns, mate choice, and birth season heterosexual relationships in free-ranging rhesus macaques. PRIMATES 35:417-433, 1994b.

Manson, J.H.; Perry, S.E. Inbreeding avoidance in rhesus macaques: Whose choice? AMERICAN JOURNAL OF PHYSICAL ANTHROPOLOGY 90:335-344, 1993.

Melnick, D.J.; Pearl, M.C.; Richard, A.F. Male migration and inbreeding avoidance in wild rhesus monkeys. AMERICAN 
JOURNAL OF PRIMATOLOGY 7:229243, 1984.

Murray, R. The evolution and functional significance of incest avoidance. JOURNAL OF HUMAN EVOLUTION 9:173-178, 1980.

Packer, C. Intergroup transfer and inbreeding avoidance in Papio anubis. ANIMAL BEHAVIOUR 27:1-36, 1979.

Palombit, R.A. Extra-pair copulations in a monogamous ape. ANIMAL BEHAVIOUR 47:721-723, 1994.

Rawlins, R.G.; Kessler, M.J. The history of the Cayo Santiago colony. Pp. $13-45$ in THE CAYO SANTIGAO MACAQUES: HISTORY, BEHAVIOR AND BIOLOGY. R.G. Rawlins; M.J. Kessler, eds. Albany, NY, SUNY Press, 1986.

Ripley, S. Infanticide in langurs and man: Adaptive advantage or social pathology? Pp. 349-390 in BIOSOCIAL MECHANISMS OF POPULA'TION REGULATION. M. Cohen; R. Malpass; H. Klein, eds. New Haven, CT, Yale University Press, 1980.

Sade, D.S.; Chepko-Sade, B.D.; Schneider, J.M.; Roberts, S.S.; Richtsmeier, J.T. BASIC DEMOGRAPHIC OBSERVATIONS
ON FREE-RANGING RHESUS MONKEYS. New Haven, CT, HRAF Press, 1985.

Small, M.F. FEMALE CHOICES: SEXUAL BEHAVIOR OF FEMALE PRIMATES. Ithaca, NY, Cornell University Press, 1993.

Sugiyama, Y. Life history of male Japanese monkeys. Pp. 255-284 in ADVANCES IN THE STUDY OF BEHAVIOR, VOL. 7. J.S. Rosenblatt; R.A. Hinde; E. Shaw; C. Beer, eds. New York, Academic Press, 1976.

Takahata, Y. Social relations between adult males and females of Japanese monkeys in the Arashiyama B Troop. PRIMATES 23: 1-23, 1982.

Tsingalia, H.M.; Rowell, T.E. The behaviour of adult male blue monkeys. ZEITSCHRIFT FÜR TIERPSYCHOLOGIE 64: 253-268, 1984.

van Noordwijk, M.A. Sexual behaviour of Sumatran long-tailed macaques (Macaca fascicularis). ZEITSCHRIFT FÜR TIERPSYCHOLOGIE 70:277-296, 1985.

Wolfe, L.D. Sexual strategies of female Japanese macaques (Macaca fuscata). HUMAN EVOLUTION 1:267-275, 1986. 